\title{
Two-dimensional echocardiography in the diagnosis of left atrial myxoma ${ }^{\star}$
}

\author{
LARRY S PERRY, JAMES F KING, HOWARD J ZEFT, JACK C MANLEY, \\ CHARLES M GROSS, L SAMUEL WANN
}

\author{
From the Medical College of Wisconsin, St Luke's Hospital, Milwaukee County Medical Complex \\ and the Veterans Administration Center, Milwaukee, Wisconsin, USA
}

SUMMARY We performed M-mode echocardiograms on 11 patients who later had left atrial myxomas removed at operation. Seven of these 11 patients were also examined with two-dimensional echocardiography. $M$-mode echocardiography showed the characteristic pattern of a left atrial mass entering the mitral orifice during diastole in nine of the 11 patients. M-mode echocardiographic findings were equivocal in two patients because a short tumour stalk prevented significant motion of the tumour. Cross-sectional echocardiography clearly showed a left atrial mass attached by a stalk to the interatrial septum in all seven patients examined, including one patient in whom the tumour was immobile. Threedimensional measurements of tumour size made from orthogonal cross-sectional echocardiographic planes were within $6 \mathrm{~mm}$ of similar measurements made on the excised tumours.

Left atrial myxomas can be readily removed using modern surgical techniques, and are a potentially curable form of heart disease. Pathologists have recognised them since the 17 th century, ${ }^{1}$ but diagnosis of this tumour during life awaited the advent of cineangiography. ${ }^{2}$ Over the past 20 years, M-mode echocardiography has come to be widely used for the diagnosis of left atrial myxomas. ${ }^{3}$ In general, it is a rapid and accurate diagnostic tool but occasionally, especially in patients with small immobile tumours, it may be inconclusive. ${ }^{4}$

Cross-sectional or two-dimensional echocardiography has recently become available and has been used to diagnose left atrial myxomas. ${ }^{56}$ Since it provides better spatial orientation than $\mathrm{M}$-mode echocardiography, and displays a larger part of the left atrium, this technique may be more sensitive, and provide better information about the size, shape, location, and motion of the tumours. This study was undertaken to examine the role of two-dimensional echocardiography in the diagnosis of left atrial myxomas.

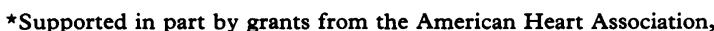
Wisconsin Affiliate, Inc., Milwaukee, WI, and the Veterans Administration Research Service, Washington, DC, USA.
}

Received for publication 16 December 1980

\section{Subjects and methods}

We reviewed the preoperative echocardiographic records of all patients who underwent surgical removal of a left atrial myxoma in our hospitals from 1975 to 1979. Eleven had been examined by M-mode echocardiography and seven of these had also been examined by two-dimensional echocardiography. Six patients were women, five were men. Their average age was 49 years, ranging from 17 years to 64 years.

M-mode echocardiograms were performed with a Smith Kline Ekoline 20A ultrasonoscope (Smith Kline Instruments, Sunnyvale, $\mathrm{Ca}$ ) and a fibreoptic strip chart recorder. The ultrasound transducer was placed in multiple rib interspaces at the left sternal border. The anterior and posterior mitral leaflets, the aortic root, aortic valve, and left atrium were well seen in each case. Two-dimensional echocardiograms were performed with a Smith Kline Ekosector I mechanical sector scanner (Smith Kline Instruments, Sunnyvale, $\mathrm{Ca}$ ) or a Toshiba SSH-10A wide angle phased array sonolayerograph (Toshiba Medical Systems, Tokyo). The heart was studied in multiple planes from all available acoustic windows, including views from the parasternal border, the cardiac apex, and the subxiphoid region. Examinations were recorded on videotape for later analysis 
in real-time, slow-motion, or stop-frame formats.

The echocardiographic records were reviewed independently by at least two observers. M-mode echocardiograms were specifically examined for the presence of a mass of echoes behind the anterior mitral leaflet during diastole. The left atrial cavity was examined for the presence of a band of echoes representing the tumour. Two-dimensional echocardiograms were examined for the presence of a mass in the atrium connected by a stalk to the interatrial septum. Three-dimensional measurements of tumour size were made from still-frame images obtained in orthogonal planes through the tumours. Similar measurements of tumour size were also made on excised surgical specimens in six of the seven patients who underwent two-dimensional echocardiography.

M-mode and two-dimensional echocardiograms were compared with one another, and related to the clinical presentation of each patient.

\section{Results}

These 11 patients with surgically proven left atrial myxomas presented with a wide variety of clinical manifestations. Two complained primarily of exertional dyspnoea, had diastolic rumbles, and were felt initially to have rheumatic mitral stenosis.
Two had pulmonary congestion and pansystolic murmurs of mitral regurgitation. The first clinical manifestation in two patients was a stroke. Another had fatigue, low-grade fever, and a systolic murmur. One patient presented as bacterial endocarditis, another with congestive heart failure, and one with chest pain and a previously negative cardiac catheterisation (left atrial angiography was not performed).

A diastolic rumble was heard in six of the 11 patients. A third heart sound (tumour plop) was heard in three. Three patients had systolic murmurs or mitral regurgitation. Two patients had atrial fibrillation.

M-mode echocardiography showed the characteristic features of a left atrial myxoma in nine of the 11 patients. Fig. 1 illustrates these typical features, which include the presence of a mass of echoes behind the anterior leaflet of the mitral valve during diastole. These echoes move out of view into the atrium during systole. In four of the nine cases a slight delay was present early in diastole after opening of the mitral valve before the tumour dropped into the mitral orifice.

Two patients did not have $\mathrm{M}$-mode echocardiographic evidence of an atrial mass entering the mitral orifice during diastole. Both patients did have multiple echoes in the left atrial cavity, but in the
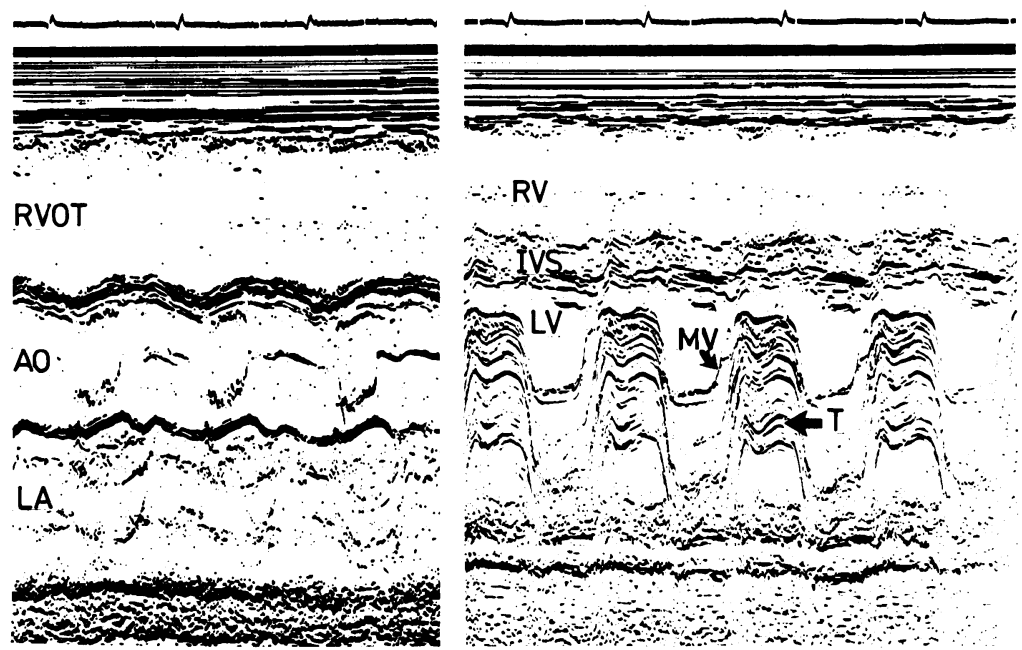

Fig. 1 Classic M-mode echocardiographic features of left atrial myxoma. RVOT, right ventricular outflow tract; $R V$, right ventricle; $A O$, aorta; $L A$, left atrium; IVS, interventricular septum; $M V$, mitral valve; $L V$, left ventricle; $T$, tumour. The multilayered echoes emanating from the left atrial tumour can be seen to prolapse into the mitral orifice during diastole, shortly after valve opening. A clear space is present during initial diastole, representing a short delay in movement of the tumour from the left atrium to the mitral orifice. Multiple echoes can be seen in the left atrium originating from the tumour mass. 

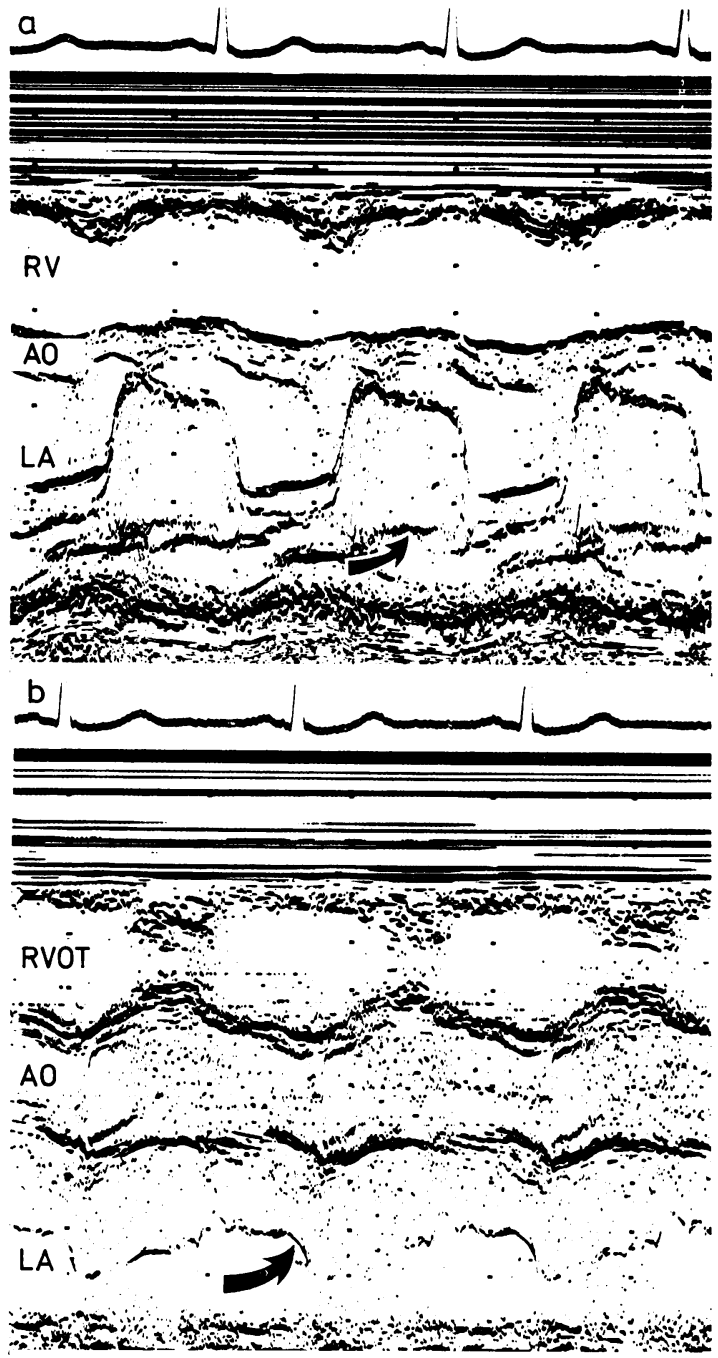

Fig. 2(a) M-mode echocardiogram of the mitral valve in a patient with an immobile left atrial myxoma. The mitral EF slope is flat, suggesting an altered pattern of left ventricular filling. The arrow points to the posterior leaflet of the mitral valve. Diastolic motion is normal in direction but the leaflet exhibits fine high-frequency fluttering, suggesting the presence of turbulent blood flow. (b) M-mode echocardiogram of the aorta and left atrium. The arrow is pointing towards a linear discrete echo which presumably represents the non-prolapsing myxoma.

absence of a characteristic motion pattern it was difficult definitely to ascribe these echoes to the mass of a myxoma. Preoperative diagnosis of left atrial myxoma was made by follow through pulmonary angiography in one patient, and by two-dimensional echocardiography in the other. At the operation in both, a very short tumour stalk preventing move- ment of the tumour during the cardiac cycle was found.

Fig. 2 illustrates the $M$-mode echocardiogram obtained from one of the patients with an immobile left atrial myxoma. Though the mitral orifice is clear during diastole (Fig. 2a), the EF slope is reduced, suggesting an alteration in the pattern of mitral flow. The mitral leaflets are thin and have a normal amplitude of motion. The posterior leaflet moves in a normal posterior direction during diastole. The posterior leaflet also shows fine diastolic fluttering, suggesting the presence of turbulent flow. The $M$ mode echocardiogram of the aortic root and left atrium (Fig. 2b) reveals a linear echo within the cavity of the left atrium.

Two-dimensional echocardiography showed an interatrial mass attached by a stalk to the interatrial septum in all seven patients examined. Fig. 3 illustrates the typical features of a mobile left atrial myxoma. During systole, the tumour rests within the cavity of the atrium, clearly separated from the thin, normal, mitral leaflets. In motion, it was seen to move down into the mitral orifice shortly after the mitral leaflets opened. The tumour is tethered to the interatrial septum by its stalk which limits its excursion into the left ventricular inflow tract.

Fig. 4 illustrates the two-dimensional echocardiogram of a non-mobile left atrial myxoma. In

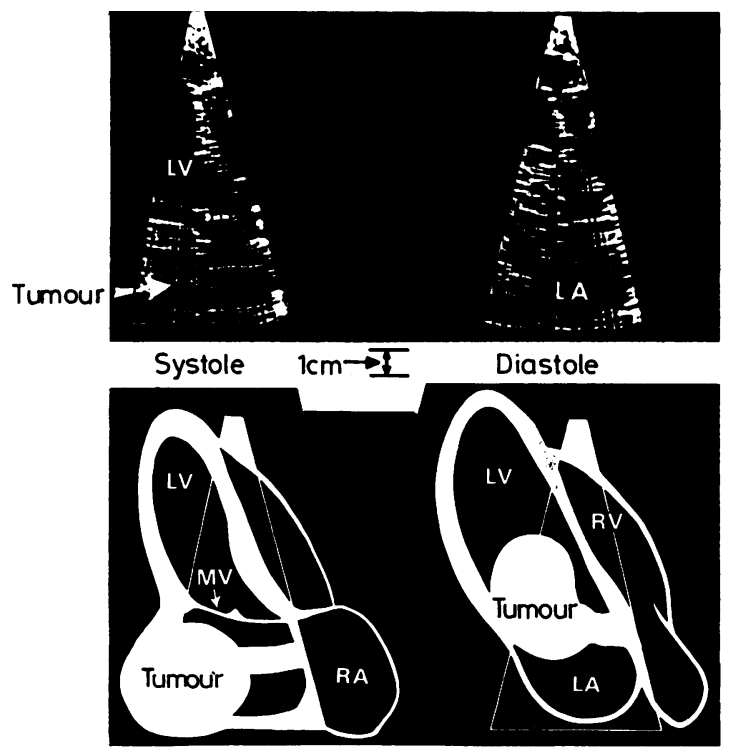

Fig. 3 Modified apical two chamber view from a patient with a prolapsing left atrial myxoma. $R A$, right atrium. The mass of the tumour is attached to the interatrial septum by a relatively long stalk. During diastole the tumour obstructs the mitral orifice. 

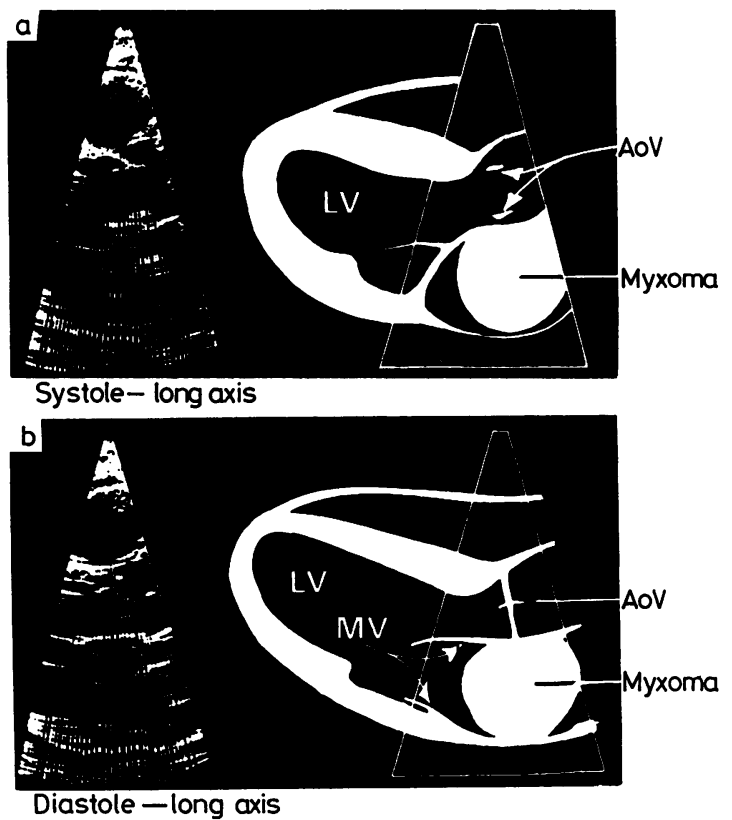

Fig. 4(a) Systolic long-axis view of a non-prolap:ing myxoma. The mass of the tumour can be seen lying within the atrium. (b) Diastolic long-axis view. The mitral leaflets have opened widely, but the mass of the tumour has remained stationary. Other views showed the tumour to be attached to the interatrial septum by a very short stalk.

his case, a very large atrial mass can be seen attached to the interatrial system by a short stalk. During diastole, the short tumour stalk prevents significant motion of the tumour and the mitral orifice itself remains unobstructed.

Three-dimensional measurements of tumour size were made from long axis, short axis, and apical four-chamber or apical two-chamber views of the tumours. Similar measurements were also made in six of the seven myxomas removed at the time of operation. Measurements made by two-dimensional echocardiography were within $6 \mathrm{~mm}$ of those made on the excised specimens in all cases.

\section{Discussion}

Cardiac myxomas are tumours of multipotential mesenchymal origin. ${ }^{7}$ They are most commonly found in the left atrium and are attached by a stalk or pedicle of variable length to the interatrial septum near the fossa ovalis. Myxomas are less commonly found in the right atrium, in the left ventricle, or in multiple sites.

Left atrial myxomas present in a protean manner.
Patients may have systemic emboli, chest pain, or heart failure and may be suspected of having endocarditis. The physical findings may suggest stenosis or regurgitation of the mitral valve, with cardiac arrhythmias; the laboratory and physical findings may point to a systemic illness. ${ }^{8-13}$ The presence of a myxoma is thus suggested by a wide variety of signs and symptoms and may be suspected in a broad spectrum of patients.

The preoperative or antemortem diagnosis of left atrial myxoma was rarely made before the advent of cardiac angiography. Though a left atrial tumour mass can be recognised as a negative shadow on follow through pulmonary angiography or on left ventriculography if significant mitral regurgitation is present, false positive and false negative results are known to occur. ${ }^{8} 10$ 14-17 The catheterisation procedure must be specifically tailored to look for a myxoma, and is associated with significant hazard. Use of the transseptal technique in particular carries a risk of dislodging part of the tumour. ${ }^{13} 1819$

M-mode echocardiography has provided a useful non-invasive means for detecting left atrial myxomas, ${ }^{13} 1516$ 20-23 with the ultrasonic appearance of the tumour as a cloud or mass of echoes filling the space posterior to the anterior mitral leaflet. Characteristically, these echoes lie in the left atrium during systole and move into the mitral orifice shortly after the onset of diastole. Careful attention must be given to proper gain settings, and the transducer must scan through the mitral valve and left atrium. Myxomas can also present as multiple, discrete linear echoes which move synchronously with the mitral valve, making definitive diagnosis difficult. ${ }^{424} \mathrm{M}$-mode echocardiography may fail to detect small or sessile tumours. ${ }^{16}$ In addition, the M-mode echocardiographic appearance of a left atrial myxoma may occasionally be confused with mitral prolapse, mitral stenosis, thrombi, or vegetations. ${ }^{3}$

Our series of patients with left atrial myxomas is similar to those previously described in that the symptoms and physical findings were variable and the diagnosis was often unsuspected. M-mode echocardiography was diagnostic in nine of the 11 patients but was inconclusive in two. Two-dimensional echocardiography correctly identified the presence of a left axial myxoma in all seven patients examined, including one patient with a sessile tumour which did not produce typical $M$-mode echocardiographic findings.

In addition, two-dimensional echocardiography accurately determined the size and shape of the tumours, vividly displayed their motion patterns, and identified their stalks, findings which correlated well with the observations made at the time of 
surgical removal.

We conclude that two-dimensional echocardiography can provide a rapid, accurate non-invasive method of diagnosis in patients with left atrial myxoma. The technique is safer than angiography and more informative than $\mathrm{M}$-mode echocardiography. It gives the size of the tumour, its shape, its mobility, and its effect on cardiac function. Since all the cardiac chambers are seen, the rare case of multiple tumours can be detected. 25 Two-dimensional echocardiography should permit the diagnosis of smaller tumours and early recurrences, ${ }^{26}$ and help to differentiate left atrial myxomas from other masses because of its ability to show the tumour stalk. Thesc advantages should make it the definitive diagnostic technique in left atrial myxoma.

\section{References}

1 Mahaim I. Les tumeurs et les polypes du coeur: e'tude anatımo-clinique. Paris: Masson et Cie, 1945.

2 Goldberg HP, Glenn F, Dotter CT, Steinberg I. Myxoma of the left atrium. Diagnosis made during life with operative and post-mortem findings. Circulation 1952; 6: 762-7.

3 Feigenbaum H. Echocardiography. 2nd ed. Philadelphia: Lea \& Febiger, 1976: 447-59.

4 Stewart JA, Warnica JW, Kirk ME, Winsberg F. Left atrial myxoma: false negative echocardiographic findings in a tumor demonstrated by coronary arteriography. Am Heart $\mathcal{f} 1979$; 98: 228-32.

5 Lappe DL, Bulkley BH, Weiss JL. Two-dimensional echocardiographic diagnosis of left atrial myxoma. Chest 1978; 74: 55-8.

6 Lewis BS, Lewis N, Popp RL, Weiss AT, Borman JB, Gotsman MS. Diagnostic value of cross-sectional echocardiography in left atrial myxoma. Isr $\mathcal{F} \mathrm{Med} \mathrm{Sci}$ 1979; 15: 426-30.

7 Prichard RW. Tumors of the heart. Arch Pathol 1951; 51: 98-128.

8 Aldridge HE, Greenwood WF. Myxoma of the left atrium. Br Heart $\mathcal{F} 1960$; 22: 189-200.

9 Goodwin JF, Stanfield CA, Steiner RE, et al. Clinical features of left atrial myxoma. Thorax 1961 ; 17: 91110.

10 Greenwood WF. Profile of atrial myxoma. Am $\mathcal{f}$ Cardiol 1968; 21: 367-75.
11 Harvey WP. Clinical aspects of cardiac tumors. $A m \mathcal{F}$ Cardiol 1968; 21: 328-43.

12 Marpole DGF, Kloster FE, Bristow JD, Griswold HE. Ataial myxoma, a continuing diagnostic challenge. Am $\mathcal{F}$ Cardiol 1969; 23: 597-602.

13 Nasser WK, Davis RH, Dillon JC, et al. Atrial myxoma. I. Clinical and pathologic features in nine cases. Am Heart f 1972; 83: 694-703.

14 Harvey JC. Myxoma of the left auricle. Ann Intern Med 1957; 47: 1067-81.

15 Popp RL, Harrison DC. Ultrasound for the diagnosis of atrial tumor. Ann Intern Med 1969; 71: 785-7.

16 Martinez EC, Giles TD, Burch GE. Echocardiographic diagnosis of left atrial myxoma. $A m \mathcal{F}$ Cardiol 1974; 33: 281-5.

17 Goodwin JF. Diagnosis of left atrial myxoma. Lancet 1963; i: 464-8.

18 Pindyck F, Peirce EC II, Baron MG, Lukban SB. Embolization of left atrial myxoma after transseptal cardiac catheterization. Am $\mathcal{F}$ Cardiol 1972; 30: 56971.

19 Stoane L, Allen JH Jr, Collins HA. Radiologic observations in cerebral embolization from left heart myxomas. Radiology 1966; 87: 262-6.

20 Effert S, Domanig E. The diagnosis of intra-atrial tumours and thrombi by the ultrasonic echo method. Ger Med Mon 1959; 4: 1-3.

21 Schattenberg TT. Echocardiographic diagnosis of left atrial myxoma. Mayo Clin Proc 1964; 43: 620-7.

22 Wolfe SB, Popp RL, Feigenbaum H. Diagnosis of atrial tumors by ultrasound. Circulation 1969; 39: 615-22.

23 Finegan RE, Harrison DC. Diagnosis of left atrial myxoma by echocardiography. N Engl f Med 1970; 282: 1022-3.

24 DeMaria AN, Vismara LA, Miller RR, Neumann A, Mason DT. Unusual echographic manifestations of right and left heart myxomas. Am $\mathcal{F}$ Med 1975; 59: 713-20.

25 Nanda NC, Gramiak R. Clinical echocardiography. St Louis: CV Mosby, 1978: 411.

26 Walton JA Jr, Kahn DR, Willis PW III. Recurrence of a left atrial myxoma. Am $\mathcal{F}$ Cardiol 1972;29: 872-6.

Requests for reprints to Dr L S Wann, Cardiovascular Section, VA Medical Center, Wood, Wisconsin 53193, USA. 